\title{
TRANSPLANTATION OF Viable Meniscal Allograft
}

\author{
Survivorship Analysis and Clinical Outcome of One Hundred Cases \\ By Peter C.M. Verdonk, MD, Alex Demurie, MD, Karl Fredrik Almqvist, MD, PhD, Eric M. Veys, MD, PhD, \\ Gust Verbruggen, MD, PhD, and René Verdonk, MD, PhD \\ Investigation performed at the Departments of Orthopaedic Surgery and Rheumatology, Ghent University Hospital, Ghent, Belgium
}

\begin{abstract}
Background: Few medium-term or long-term reports on meniscal allograft transplantations are available. In this study, we present the results of a survival analysis of the clinical outcomes of our first 100 procedures involving transplantation of viable medial and lateral meniscal allografts performed in ninety-six patients.
\end{abstract}

Methods: Thirty-nine medial and sixty-one lateral meniscal allografts were evaluated after a mean of 7.2 years. Survival analysis was based on specific clinical end points, with failure of the allograft defined as moderate occasional or persistent pain or as poor function. An additional survival analysis was performed to assess the results of the sixtynine procedures that involved isolated use of a viable allograft (twenty of the thirty-nine medial allograft procedures and forty-nine of the sixty-one lateral allograft procedures) and of the thirteen viable medial meniscal allografts that were implanted in combination with a high tibial osteotomy in patients with initial varus malalignment of the lower limb.

Results: Overall, eleven $(28 \%)$ of the thirty-nine medial allografts and ten $(16 \%)$ of the sixty-one lateral allografts failed. The mean cumulative survival time (11.6 years) was identical for the medial and lateral allografts. The cumulative survival rates for the medial and lateral allografts at ten years were $74.2 \%$ and $69.8 \%$, respectively. The mean cumulative survival time and the cumulative survival rate for the medial allografts used in combination with a high tibial osteotomy were 13.0 years and $83.3 \%$ at ten years, respectively.

Conclusions: Transplantation of a viable meniscal allograft can significantly relieve pain and improve function of the knee joint. Survival analysis showed that this beneficial effect remained in approximately $70 \%$ of the patients at ten years. This study identified the need for a prospective study comparing patients with similar symptoms and clinical findings treated with and without a meniscal allograft and followed for a longer period with use of clinical evaluation as well as more objective documentation tools regarding the actual fate of the allograft itself and the articular cartilage.

Level of Evidence: Therapeutic Level IV. See Instructions to Authors for a complete description of levels of evidence.

$\mathrm{T}$ he meniscus plays an important role in the complex biomechanics of the knee joint. It has functions in load bearing, load transmission, shock absorption, joint stability, joint lubrication, and joint congruity. Removal of this important anatomical structure eventually leads to degenerative changes of the articular cartilage $\mathrm{e}^{1-3}$. Therefore, meniscal tissue should be preserved whenever possible. When the meniscus has been completely lost, transplantation of a meniscal allograft has been a therapeutic option with favorable results, in terms of pain reduction and functional improvement, in the medium and long term ${ }^{4.7}$. These improvements are presumably due to an increase in contact area and thus a decrease in contact peak stress compared with a meniscectomized $\mathrm{knee}^{8-11}$. While decreases in contact stresses can result in pain relief and improved function, there is no reasonable proof that delayed meniscal transplantation prevents or slows cartilage degeneration in either compartment $t^{6,12}$.
One way to determine the clinical effectiveness of this investigational procedure is to analyze the duration of survival of the allograft, especially when the study involves patients with different durations of follow-up. In this study, we present a survival analysis carried out at a minimum of two years after our first 100 procedures involving transplantation of a viable meniscal allograft.

\section{Materials and Methods \\ Patients}

The indication for transplantation of a viable meniscal al-

I lograft was moderate-to-severe pain in a younger patient who had undergone a previous total meniscectomy, was not old enough to be considered for a knee joint replacement, and had good alignment of the lower limb and a stable joint. When there was axial malalignment of the lower limb or instability of the knee joint, a corrective osteotomy or stabilization 
The Journal of Bone \& JoInt Surgery · JBJS.Org

TABLE I Femorotibial Alignment and Preoperative Cartilage Status According to the Outerbridge Classification ${ }^{13}$ in the Allograft Subgroups*

\begin{tabular}{lcc|}
\hline & Femorotibial Alignment (deg) & Preop. Cartilage Grade \\
\hline Medial meniscal allografts & $5.3 \pm 2.7$ & $2.6 \pm 0.8$ \\
Medial meniscal allografts and high tibial osteotomy & $7.1 \dagger \pm 2.8$ & $2.9 \ddagger \pm 0.8$ \\
Isolated medial meniscal allografts & $4.3 \dagger \pm 2.3$ & $2.4 \ddagger \pm 0.7$ \\
Lateral meniscal allografts & $6.1 \pm 2.5$ & $2.5 \pm 1$ \\
Isolated lateral meniscal allografts & $6.0 \pm 2.2$ & $2.4 \pm 1$ \\
\hline
\end{tabular}

$*$ The values are given as the mean and standard deviation. †Femorotibial axial alignment differed significantly between the medial meniscal allografts transplanted in combination with a high tibial osteotomy and the isolated medial meniscal allografts $(p=0.006$, Mann-Whitney $U$ test). $\neq$ The preoperative cartilage grade according to Outerbridge ${ }^{13}$ differed significantly between the medial meniscal allografts transplanted in combination with a high tibial osteotomy and the isolated medial meniscal allografts $(p=0.062$, Mann-Whitney $U$ test).

procedure was performed at the time of the transplantation.

One hundred and five meniscal allografts were transplanted in 101 patients between 1989 and 2001. Two patients received a lateral meniscal allograft bilaterally, and two patients received medial and lateral meniscal allografts in the same knee. All operations were performed at different points of time.

The mean age (and standard deviation) at the time of the transplantation was $35.0 \pm 6.7$ years (range, sixteen to fifty years). Four meniscal allografts were transplanted in four patients who lived outside of the country and could not be contacted after the operation for follow-up evaluation. One patient was lost to follow-up immediately after the transplantation procedure. This resulted in 100 meniscal allografts being available for the survival analysis, with a mean duration of follow-up of $7.2 \pm 3.6$ years (range, 0.5 to 14.5 years) and a minimum duration of two years (or until failure). The followup rate was $95.2 \%$.

Thirty-nine medial allografts and sixty-one lateral allografts were implanted into seventy men and twenty-six women.

Postoperative lower-limb alignment was assessed in all patients on weight-bearing roentgenograms by measuring the anatomical femorotibial axis (Table I and Appendix). These measurements were performed in duplicate by a single observer with a one-month interval between observations (intraclass correlation coefficient $=0.851, \mathrm{p}<0.001$, Spearman rho test). The roentgenograms were made at the time that the osteotomy site was noted to be healed or within a six-month period after the surgery.

The status of the articular cartilage was evaluated at the time of transplantation and at the time of failure with use of a modification of the Outerbridge ${ }^{13}$ grading system. For example, a lesion that was graded between III and IV was recorded in our file as 3/4 and was given a value of 3.5 (Table I and Appendix). Also, grade $\mathrm{V}$, indicating bone-on-bone contact, was added to the Outerbridge system.

\section{Surgical Technique}

All patients underwent transplantation of a viable meniscal allograft. The allograft was harvested within twenty-four hours post mortem under strictly aseptic conditions in the operating theater. Donor tissues were obtained from the Ghent University Hospital Tissue Bank. The donors had died from injuries or a disease of short duration, with the majority dying as a result of a cerebrovascular incident or an automobile accident. A maximum age of forty-five years was set for the donors. None had received corticosteroids or cytostatic drugs. The allograft was maintained in culture for two weeks in Dulbecco Modified Eagle Medium (DMEM; Gibco Invitrogen, Merelbeke, Belgium) supplemented with $20 \%$ autologous serum prior to transplantation. Previous studies have demonstrated that meniscal cells remain viable and continue to synthesize their extracellular matrix molecules in this culture system ${ }^{14}$. During

TABLE II Types of Concomitant Surgery

\begin{tabular}{|c|c|c|c|c|c|c|}
\hline & \multicolumn{2}{|c|}{$\begin{array}{l}\text { Medial and Lateral } \\
\text { Meniscal Allografts } \\
\text { in Same Knee }\end{array}$} & \multicolumn{2}{|c|}{$\begin{array}{l}\text { High Tibial Osteotomy } \\
\text { for Varus Malalignment } \\
\text { of Lower Limb }\end{array}$} & \multicolumn{2}{|c|}{$\begin{array}{l}\text { Femoral Varus Osteotomy } \\
\text { for Valgus Malalignment } \\
\text { of Lower Limb }\end{array}$} \\
\hline & No. & $\%$ & No. & $\%$ & No. & $\%$ \\
\hline Medial meniscal allografts & 2 & 5 & 13 & 33 & 0 & 0 \\
\hline Lateral meniscal allografts & 2 & 3 & 2 & 3 & 2 & 3 \\
\hline Total & $4 *$ & & 15 & & 2 & \\
\hline
\end{tabular}


The JOURnAL of BOnE \& JOINT SURGERY • JBIS. ORG VOLUme 87-A · NUMBER 4 A APril 2005
TRANSPLANTATION OF

Viable Meniscal Allograft the culture period, there was ample time to screen the donors for transmissible diseases.

All patients were operated on by the senior surgeon (R.V.). Access to the knee joint was achieved by a lateral or medial parapatellar arthrotomy. The insertion of the lateral collateral ligament and popliteus tendon or the medial collateral ligament was detached with an osteotomy on the femoral $\operatorname{side}^{15}$. The osteotomy fragment was later restored by screw fixation or stapling. The meniscal remnant was excised, leaving only a bleeding meniscal rim. The meniscal rim deserves surgical attention, as it serves as a strong envelope encapsulating the medial or lateral compartment of the knee. The rim should not be resected or transected during the operation, as doing so leads to a breach in the envelope. The viable meniscal allograft was then securely sutured to this rim with use of horizontal polydioxanone surgical sutures (PDS II; Ethicon, Somerville, New Jersey) every $3 \mathrm{~mm}$ in an all-inside fashion. Bone-block fixation to the tibial plateau was not used to augment the meniscal fixation. Instead, the anterior and posterior horns of the transplanted meniscus were sutured to the remnant native horns on the tibia. This procedure has been described in detail elsewhere ${ }^{15}$.

Postoperative rehabilitation consisted of three weeks of non-weight-bearing with mobilization of the knee, within pain limits, with limitation of flexion to $60^{\circ}$. After three weeks, the patients were allowed to flex the knee to $90^{\circ}$ and to start partial weight-bearing. At six weeks, all patients were allowed to walk with one crutch.

\section{Concomitant Procedures}

Concomitant surgical procedures, judged to be essential in a few patients, included a high tibial osteotomy, femoral varus osteotomy, anterior cruciate ligament repair, osteochondral plug transfer, and microfracture (Table II). At the time of the meniscal allografting, a high tibial valgus osteotomy was performed in association with thirteen of the thirty-nine medial allograft transplantations and two of the sixty-one lateral allograft procedures (Table II). The indication for a concomitant high tibial osteotomy in the patients treated with a medial transplant was varus malalignment of the lower limb. A high tibial osteotomy was performed in the two patients with a lateral allograft to ensure decompression of the medial compartment because of degeneration of the articular cartilage in both the medial and the lateral compartment. It was thought that shifting the mechanical axis toward the lateral compartment could decompress the degenerated medial compartment while the lateral compartment was protected by the lateral allograft. This procedure was performed only twice, in the early 1990s. Two lateral meniscal allograft transplantations were performed in association with a femoral varus osteotomy to correct valgus malalignment.

The anterior cruciate ligament was reconstructed at the time of three of the medial allograft procedures and none of the lateral allograft procedures (Table II). The reconstruction was performed with an intra-articular double-loop tibialis posterior tendon allograft with use of a previously described technique $^{16}$. Thus, the population that we analyzed consisted of patients with stable knees or with knees that had been stabilized prior to meniscal allografting.

In most cases, the cartilage degeneration seen at the time of the transplantation was limited to Outerbridge grade-II or beginning grade-III changes (Table I and Appendix) ${ }^{13}$. Borderline indications for meniscal allograft transplantation-i.e., focal grade-IV degenerative changes of the cartilage-were treated with concomitant cartilage surgery, such as the autologous osteochondral plug transfer (OATS; Arthrex, Naples, Florida) (four of the sixty-one lateral allograft procedures and none of the medial allograft procedures) or the microfracture technique (Osteoprep; Linvatec, Largo, Florida) (one of the thirtynine medial allograft procedures and two of the sixty-one lateral allograft procedures) (Table II). All of these patients were operated on after 1998. Prior to that date, no specific treatment for this type of cartilage lesion was performed.

Two patients underwent transplantation of both a medial and a lateral meniscal allograft in the same knee joint, as stated earlier.

Overall, nineteen (49\%) of the thirty-nine medial allograft transplantations and only twelve $(20 \%)$ of the sixty-one lateral allograft transplantations were associated with another procedure in the index knee joint.

\section{Clinical Evaluation of the Knee Joint}

Since at present there is no specific system for scoring the results of meniscal surgery, a modification of the Hospital for Special Surgery (HSS) scoring system was used to prospectively evaluate the function of the involved knee joint and the meniscal

TABLE II (continued)

\begin{tabular}{|c|c|c|c|c|c|c|c|c|c|}
\hline \multicolumn{2}{|c|}{$\begin{array}{l}\text { Anterior Cruciate } \\
\text { Ligament } \\
\text { Reconstruction }\end{array}$} & \multicolumn{2}{|c|}{$\begin{array}{l}\text { Osteochondral } \\
\text { Plug Transfer }\end{array}$} & \multicolumn{2}{|c|}{ Microfracture } & \multicolumn{2}{|c|}{$\begin{array}{l}\text { Isolated Allograft } \\
\text { Procedures }\end{array}$} & \multicolumn{2}{|c|}{ Total } \\
\hline No. & $\%$ & No. & $\%$ & No. & $\%$ & No. & $\%$ & No. & $\%$ \\
\hline 3 & 8 & 0 & 0 & 1 & 3 & 20 & 51 & 39 & 100 \\
\hline 0 & 0 & 4 & 7 & 2 & 3 & 49 & 80 & 61 & 100 \\
\hline 3 & & 4 & & 3 & & 69 & & 100 & \\
\hline
\end{tabular}


TABLE III Preoperative and Postoperative* Pain Scores in the Allograft Subgroups

\begin{tabular}{|c|c|c|c|c|c|c|c|c|c|c|}
\hline & \multicolumn{8}{|c|}{ Pain Score (Max., 50 Points) } & \multirow[b]{3}{*}{ P Value } & \multirow{3}{*}{$\begin{array}{c}\text { Mean } \\
\text { Duration of } \\
\text { Follow-up (yr) }\end{array}$} \\
\hline & \multicolumn{4}{|c|}{ Preoperative } & \multicolumn{4}{|c|}{ Postoperative } & & \\
\hline & Median & $\begin{array}{l}\text { 25th-75th } \\
\text { Percentile }\end{array}$ & Mean & $\begin{array}{l}\text { Standard } \\
\text { Deviation }\end{array}$ & Median & $\begin{array}{l}\text { 25th-75th } \\
\text { Percentile }\end{array}$ & Mean & $\begin{array}{l}\text { Standard } \\
\text { Deviation }\end{array}$ & & \\
\hline $\begin{array}{l}\text { Medial meniscal } \\
\text { allografts }\end{array}$ & 10 & $10-20$ & 11.9 & 3.9 & 40 & $30-45$ & 34.2 & 17.2 & 0.000 & 8.5 \\
\hline $\begin{array}{l}\text { Medial meniscal } \\
\text { allografts and high } \\
\text { tibial osteotomy }\end{array}$ & 10 & $10-20$ & 14.2 & 10.0 & 45 & $30-50$ & 37.7 & 16.2 & 0.008 & 10.1 \\
\hline $\begin{array}{l}\text { Isolated medial } \\
\text { meniscal allografts }\end{array}$ & 10 & $10-20$ & 11.6 & 7.7 & 40 & $15-50$ & 33.5 & 18.6 & 0.001 & 8.2 \\
\hline $\begin{array}{l}\text { Lateral meniscal } \\
\text { allografts }\end{array}$ & 10 & $10-20$ & 14.8 & 9.3 & 45 & $40-50$ & 42.7 & 10.3 & 0.000 & 6.2 \\
\hline $\begin{array}{l}\text { Isolated lateral } \\
\text { meniscal allografts }\end{array}$ & 10 & $10-20$ & 15.3 & 9.4 & 45 & $40-50$ & 42.7 & 10.1 & 0.000 & 6.3 \\
\hline
\end{tabular}

allograft ${ }^{17}$. This system is used to evaluate pain, function, range of motion, flexion deformity, and instability of the involved knee (see Appendix). Therefore, it is an indicator of overall knee function ${ }^{17}$. This rating system has been used to determine knee function in previous reviews of the results of meniscal allografting procedures and of fresh osteochondral allograft procedures in combination with meniscal allografting ${ }^{15,18,19}$.

Since meniscal allografting specifically relieves pain and improves function, the pain score and functional score of the modified HSS system were used for the evaluation of the clinical outcome and for the survival analysis ${ }^{4-7}$. The involved knee joint was evaluated by experienced examiners preoperatively and on a yearly basis postoperatively.

Statistical comparison between the preoperative pain and function scores and the scores at the time of the latest follow-up or at the time of failure was performed with use of the nonparametric Wilcoxon signed-rank test, since the postoperative score distribution was determined to be non-normal according to the Kolmogorov-Smirnov and Shapiro-Wilk tests $(\mathrm{p}<0.05)$. Accordingly, the median scores and the 25th and 75 th percentiles along with the mean scores and the standard deviations are presented for all subgroups. The level of significance was set at $\mathrm{p}<0.05$.

\section{Clinical Kaplan-Meier Survival Analysis}

Survival analysis was based on specific clinical end points. A failure of the allograft was defined as moderate or severe occasional or persistent pain or as poor knee function. A modified HSS subscore for pain of $<30$ points indicates moderate occasional or persistent pain. A modified HSS function score of $<80$ points was arbitrarily chosen to define poor function.

Second-look arthroscopy was performed in cases of failure or for investigational purposes. A number of patients agreed to undergo investigational follow-up arthroscopy of the knee joint at the time of operative removal of a fixation screw or staple or another procedure not related to the knee joint. The indication for removal of the device was frequent irritation of the soft tissues around it. Data from these investigational follow-up arthroscopic procedures were used for a separate analysis ${ }^{20}$. At the time of the second-look arthroscopy, the integrity of the meniscal allograft and its capsular attachment as well as the appearance of the articular cartilage surface was evaluated. A graft that had failed mechanically and had resulted in a pain score of $<30$ points and/or a function score of $<80$ points was characterized either by severe degeneration of the allograft or by allograft-capsular detachment noted at the time of the second-look arthroscopy. Prominent degenerative changes in the articular cartilage were considered to be the consequence of a malfunctioning meniscal allograft, even if the allograft itself showed limited or no signs of degeneration.

In the case of mechanical failure due to major degeneration and/or tearing, the meniscal allograft was partially resected with use of standard procedures. In the case of mechanical failure due to allograft-capsular detachment, sutures were placed according to a standard protocol ${ }^{21}$.

Some knees were converted to a total or unicompartmental knee arthroplasty. All such knees were considered to be failures in the survival study. The date of failure was considered to be the date at which the modified HSS pain or function score fell below the threshold.

Postoperative magnetic resonance imaging was performed in a subset of patients for a separate analysis ${ }^{22}$. Although magnetic resonance imaging has an established role in the diagnosis of meniscal pathology, its value in the postoperative assessment of meniscal allografts is less clear. The corre- 
TABLE IV Preoperative and Postoperative* Function Scores in the Allograft Subgroups

\begin{tabular}{|c|c|c|c|c|c|c|c|c|c|c|}
\hline & \multicolumn{8}{|c|}{ Function Score (Max., 100 Points) } & \multirow[b]{3}{*}{$P$ Value } & \multirow{3}{*}{$\begin{array}{c}\text { Mean } \\
\text { Duration of } \\
\text { Follow-up (yr) }\end{array}$} \\
\hline & \multicolumn{4}{|c|}{ Preoperative } & \multicolumn{4}{|c|}{ Postoperative } & & \\
\hline & Median & $\begin{array}{l}\text { 25th-75th } \\
\text { Percentile }\end{array}$ & Mean & $\begin{array}{l}\text { Standard } \\
\text { Deviation }\end{array}$ & Median & $\begin{array}{l}\text { 25th-75th } \\
\text { Percentile }\end{array}$ & Mean & $\begin{array}{l}\text { Standard } \\
\text { Deviation }\end{array}$ & & \\
\hline $\begin{array}{l}\text { Medial meniscal } \\
\text { allografts }\end{array}$ & 60 & $50-75$ & 58.6 & 23.6 & 100 & $80-100$ & 83.7 & 25.14 & 0.000 & 8.5 \\
\hline $\begin{array}{l}\text { Medial meniscal } \\
\text { allografts and high } \\
\text { tibial osteotomy }\end{array}$ & 60 & $50-80$ & 62.5 & 12.1 & 100 & $80-100$ & 86.2 & 22.3 & 0.032 & 10.1 \\
\hline $\begin{array}{l}\text { Isolated medial } \\
\text { meniscal allografts }\end{array}$ & 65 & $40-75$ & 58.7 & 27.0 & 100 & $80-100$ & 83.7 & 26.3 & 0.014 & 8.2 \\
\hline $\begin{array}{l}\text { Lateral meniscal } \\
\text { allografts }\end{array}$ & 60 & $50-70$ & 61.1 & 18.4 & 100 & $90-100$ & 91.64 & 17.4 & 0.000 & 6.2 \\
\hline $\begin{array}{l}\text { Isolated lateral } \\
\text { meniscal allografts }\end{array}$ & 60 & $50-75$ & 61.5 & 19.5 & 100 & $90-100$ & 92.6 & 15.9 & 0.000 & 6.3 \\
\hline Overall & 60 & $50-70$ & 60.1 & 20.5 & 100 & $90-100$ & 88.6 & 21.0 & 0.000 & 7.2 \\
\hline
\end{tabular}

lation between the findings of magnetic resonance imaging and the clinical outcome has been reported to be poor ${ }^{22,23}$. Hence, magnetic resonance imaging was not used to define clinical failure.

Survivorship analysis was performed for the medial and lateral meniscal allografts separately. Since a large number of these allograft procedures were performed with a concomitant procedure, additional survival analyses were performed for the isolated allograft procedures and for the allograft procedures combined with high tibial osteotomy.

Two patients died, of causes not related to the allograft transplantation, during the follow-up period. The most recent modified HSS scores for these two patients were used for the analysis. Since these scores were higher than the threshold, the data were included in the survival analysis and the allografts were not considered to be failures.

Kaplan-Meier survivorship analysis was performed with use of SPSS 11.0 software for Windows XP (SPSS, Chicago, Illinois) and was based on the end points stated earlier. The analysis examined the distribution of the times between the meniscal allograft transplantation and failure. However, these data included some censored cases-i.e., cases for which the second event (failure) was not recorded because the allograft had not failed by the end of the study. The Kaplan-Meier procedure was a method of estimating time-to-event models in the presence of censored cases.

The study protocol was approved by the ethics committee of Ghent University Hospital, and informed consent was obtained from each patient enrolled in the study.

\section{Failure Analysis}

To test possible predictors of clinical failure, a comparison of the mean values for the initial status of the cartilage, femorotib- ial alignment, preoperative pain score, and preoperative function score between the patients who had a failure and those who did not was performed in each subgroup with use of the MannWhitney test. The level of significance was set at $p<0.05$.

Progression of degeneration of the articular cartilage at the time of failure was measured by subtracting the initial Outerbridge $^{13}$ grade from the grade at the time of the failure. The status of the meniscal allograft was considered to be normal ( 0 points) at the time of transplantation, and it was scored as normal ( 0 points), having minor degeneration ( 1 point), or having severe degeneration ( 2 points) at the time of failure. Possible correlations between these two parameters were investigated with use of the nonparametric two-tailed Spearman rho correlation.

\section{Results}

\section{Clinical Outcome}

7 he modified HSS pain and function scores improved sig1 nificantly between the preoperative and the latest followup visits in the series as a whole as well as in all investigated subgroups. The overall median and mean pain scores (maximum, 50 points) improved from 10 and 13.7 points preoperatively to 45 and 39.4 points at the time of final follow-up. The overall median and mean function scores (maximum, 100 points) improved from 60 and 60.1 points preoperatively to 100 and 88.6 points at the time of final follow-up. The pain and function scores for the specific subgroups are presented in Tables III and IV, respectively.

\section{Kaplan-Meier Survival Analysis}

According to the clinical end-point criteria for failure, twentyone allografts (eleven medial and ten lateral) failed in eighteen patients, including two who had a lateral transplant bilaterally 
The JOURnAL of BOnE \& JOINT SURGERY • JBJS.ORG Volume 87-A · Number $4 \cdot$ April 2005
TRANSPLANTATION OF

Viable Meniscal Allograft and one who had unilateral medial and lateral transplants. Two patients with a failure of a medial allograft had undergone a high tibial osteotomy and one, an anterior cruciate repair. None of the patients with a failure of a lateral allograft had undergone an osteotomy, an anterior cruciate repair, an osteochondral plug transfer, or a microfracture at the time of transplantation or later.

Overall, eleven (28\%) of the thirty-nine medial allografts failed, at a mean (and standard deviation) of $6.0 \pm 3.8$ years (range, 1.2 to 13.4 years) postoperatively, and ten (16\%) of the sixty-one lateral allografts failed, at a mean of $4.8 \pm 2.8$ years (range, 0.5 to 9.7 years) postoperatively.

On the basis of these results, a Kaplan-Meier survivorship plot was drawn for the lateral and medial allografts (Fig. 1-A). The mean cumulative survival time for the medial meniscal allografts was 11.6 years (standard error, 0.8 year; $95 \%$ confidence interval, 10.1 to 13.1 years). The mean survival time for the lateral meniscal allografts was 11.6 years (standard error, 0.7 year; 95\% confidence interval, 10.3 to 12.9 years) (Table V).

The cumulative survival rate for the medial allografts was $86.2 \%$ (standard deviation, $5.7 \%$ ) at five years, $74.2 \%$ (standard deviation, 7.4\%) at ten years, and 52.8\% (standard deviation, $14.4 \%$ ) at 14.5 years. The cumulative survival rates for the lateral transplants at five, ten, and fourteen years were 90.2\% (standard deviation, 4.2\%), 69.8\% (standard deviation, $9.7 \%$ ), and $69.8 \%$ (standard deviation, 9.7\%), respectively. The survival plots for the medial and lateral allografts did not differ significantly ( $p=0.733$, log-rank test).

We performed an additional survival analysis of the sixtynine isolated allograft procedures (twenty of the thirty-nine medial allograft procedures and forty-nine of the sixty-one lateral allograft procedures). The Kaplan-Meier plot is shown in Figure 1-B. Overall, seven (35\%) of the twenty isolated medial allografts and nine $(18 \%)$ of the forty-nine isolated lateral allografts failed at a mean of 6.8 years (standard deviation, 4.6 years; range, 1.2 to 12.2 years) and 4.8 years (standard deviation, 2.9 years; range, 0.5 to 9.7 years), respectively. The mean cumulative survival time for the isolated medial meniscal allografts was 10.7 years (standard error, 1.0 year; $95 \%$ confidence interval, 8.8 to 12.6 years) (Table V). The mean survival time for

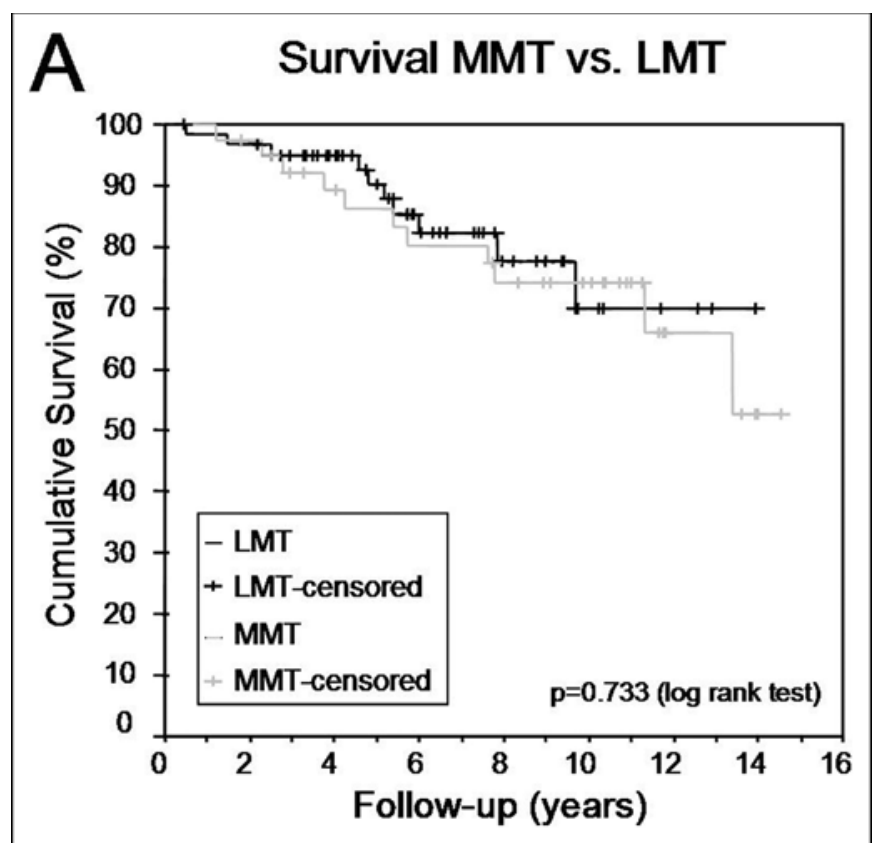

Fig. 1-A

Figs. 1-A, 1-B, and 1-C Kaplan-Meier cumulative survival plots. Abscissa $=$ years of follow-up, and ordinate = percentage of cumulative survival. Cumulative survival rates (and standard error) at the five, ten, and fourteen-year time-points for the patient subgroups are given in Table V. Fig. 1-A Survival of the total group of medial meniscal allografts (MMT) compared with that of the total group of lateral meniscal allografts (LMT).

the isolated lateral meniscal allografts was 11.4 years (standard error, 0.8 year; $95 \%$ confidence interval, 9.9 to 12.85 years). The cumulative survival rate for the isolated medial allografts was $84.1 \%$ (standard deviation, $8.4 \%$ ) at five years, $72.4 \%$ (standard deviation, $10.6 \%$ ) at ten years, and $27.2 \%$ (standard deviation, $21.1 \%$ ) at 13.4 years. The cumulative survival rates for the isolated lateral transplants were $90.9 \%$ (standard deviation, $4.4 \%$ ), $66.8 \%$ (standard deviation, $11.3 \%$ ), and $66.8 \%$ (standard deviation, $11.3 \%)$ at five, ten, and fourteen years, respectively. The

TABLE V Failures, Survival Time, and Mean Cumulative Survival Rate in the Allograft Subgroups

\begin{tabular}{|c|c|c|c|c|c|c|c|c|}
\hline & \multicolumn{2}{|c|}{ Cases } & \multicolumn{2}{|c|}{ Failures } & \multirow{2}{*}{$\begin{array}{l}\text { Survival } \\
\text { Time* }\end{array}$} & \multicolumn{3}{|c|}{ Cumulative Survival Rate $†$} \\
\hline & No. & $\%$ & No. & $\%$ & & $5 \mathrm{Yr}$ & $10 \mathrm{Yr}$ & $14 \mathrm{Yr}$ \\
\hline Medial meniscal allografts & 39 & 100 & $11 / 39$ & 28 & $11.6 \pm 0.8$ & $86.2 \pm 5.7$ & $74.2 \pm 7.4$ & $52.8 \pm 14.4$ \\
\hline $\begin{array}{l}\text { Isolated medial meniscal } \\
\text { allografts }\end{array}$ & $20 / 39$ & 51 & $7 / 20$ & 35 & $10.7 \pm 1.0$ & $84.1 \pm 8.4$ & $72.4 \pm 10.6$ & $27.2 \pm 21.1$ \\
\hline $\begin{array}{l}\text { Isolated lateral meniscal } \\
\text { allografts }\end{array}$ & $49 / 61$ & 80 & $9 / 49$ & 18 & $11.4 \pm 0.8$ & $90.9 \pm 4.4$ & $66.8 \pm 11.3$ & $66.8 \pm 11.3$ \\
\hline
\end{tabular}


The JOURnAl of BOnE \& JOINT SURGERY • JBIS. ORG Volume 87-A · Number $4 \cdot$ April 2005
TRANSPLANTATION OF

Viable Meniscal Allograft

\section{Survival of isol.MMT vs. isol.LMT}

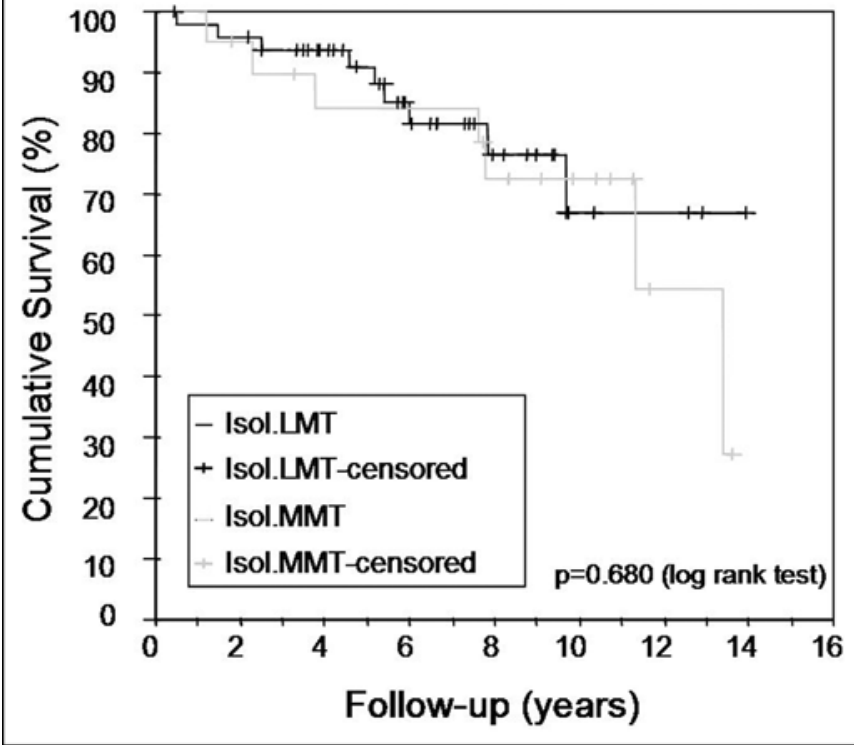

Fig. 1-B

Survival of the isolated medial meniscal allografts (Isol.MMT) com-

pared with that of the isolated lateral meniscal allografts (Isol.LMT).

survival plots for the isolated medial and lateral allograft procedures did not differ significantly from one another $(\mathrm{p}=0.680$, log-rank test).

Since a large number of medial transplants (thirteen) were combined with a high tibial osteotomy, a comparison was made between the grafting procedures performed with a high tibial osteotomy and those done without a high tibial osteotomy. Only two of the thirteen medial grafting procedures performed with a high tibial osteotomy failed compared with seven of the twenty that were done as isolated transplants. The survival plot is shown in Figure 1-C. The mean cumulative survival time for the medial allografts associated with a high tibial osteotomy was 13.0 years (standard error, 1.0 year; 95\% confidence interval, 11.1 to 15.0 years), and the survival rate was $83.3 \%$ (standard deviation, $10.7 \%$ ) at ten years (Table V). The difference between the medial grafting procedures performed with and without a high tibial osteotomy was not significant $(\mathrm{p}=$ $0.156, \log$-rank test) as a result of the small number of cases.

\section{Failure Analysis}

No significant difference concerning the initial cartilage status, femorotibial alignment, or preoperative function was observed between the knees in which the graft failed and those in which it did not fail in any subgroup. The preoperative pain score, however, differed significantly between the failures and the non-failures in both the total medial allograft subgroup and the isolated medial allograft subgroup $(\mathrm{p}=0.008$ and 0.013 , respectively). This difference was not observed in the other subgroups (Table VI).

Of the twenty-one failures, seventeen (81\%; nine medial allografts and eight lateral allografts) were characterized by pro- gression of articular cartilage degeneration and twenty (95\%; eleven medial allografts and nine lateral allografts) showed progression of allograft degeneration at the time of failure. Eight of the failed allografts showed severe degeneration and twelve showed only minor degenerative changes at arthroscopy. One of the knees, with a failure due to capsular detachment, had a normal meniscal allograft. The degenerative changes in the articular cartilage were classified as Outerbridge ${ }^{13}$ grade $\mathrm{V}$ in nine cases, grade IV in two, grade III in six, grade II/III in two, and grade II in two (see Appendix). Of the twenty-one knees with a failure, nine (six with a medial allograft, two with a lateral allograft, and one with unilateral medial and lateral allografts) were converted to a total or unicompartmental knee prosthesis at a mean of 6.3 years (standard deviation, 3.6 years; range, one to twelve years) because of progression of cartilaginous degeneration (grade V in nine cases and grade III in one) and/or meniscal degeneration (severe in five cases and minor in five). Two allografts (one medial and one lateral) had to be reattached because of meniscocapsular detachment. Both healed uneventfully.

Higher grades of articular cartilage degeneration at the time of failure were associated with significantly more severe degeneration of the meniscal allograft (Spearman rho correlation coefficient, $0.509 ; \mathrm{p}=0.018$, indicating a moderate correlation).

Detailed scatterplots depicting these degenerative changes of the articular cartilage and meniscal allografts are shown in the Appendix.

\section{Discussion}

$T^{t}$ is difficult to compare previously published results with our 1 results because of large differences in meniscal preservation

\section{Survival of MMT+HTO vs. Isol.MMT}

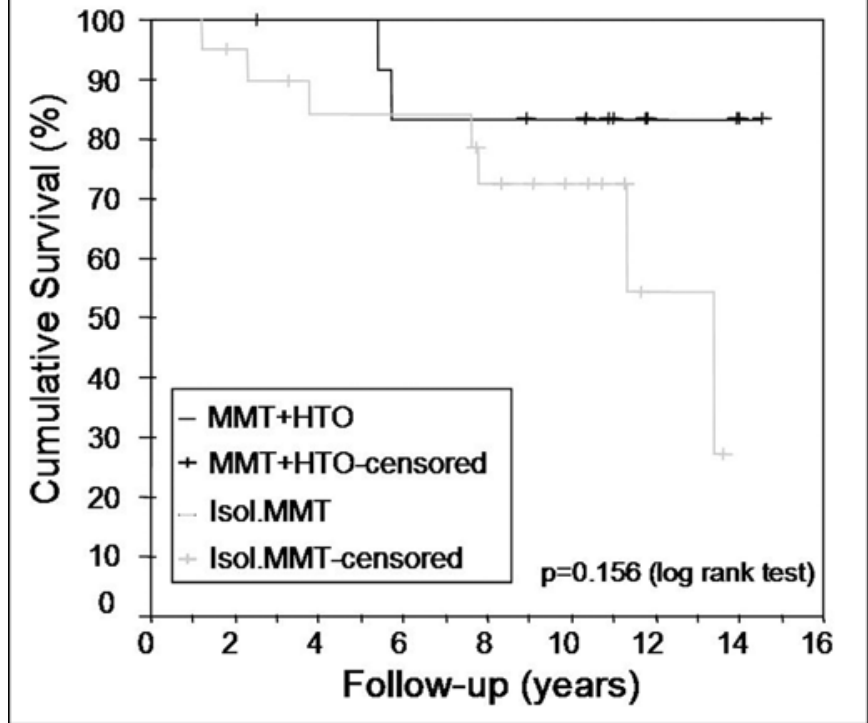

Fig. 1-C

Survival of the medial meniscal allografts transplanted in combination with a high tibial osteotomy (MMT+HTO) compared with that of the isolated medial meniscal allografts (Isol.MMT). 
TABLE VI Comparison of Possible Predictors of Clinical Failure in the Allograft Subgroups

\begin{tabular}{|c|c|c|c|c|c|c|}
\hline & \multicolumn{3}{|c|}{ Femorotibial Alignment (deg) } & \multicolumn{3}{|c|}{ Preop. Cartilage Grade ${ }^{13}$} \\
\hline Medial meniscal allografts & $5.3 \pm 2.8$ & $5.3 \pm 2.6$ & 0.96 & $2.6 \pm 0.9$ & $2.6 \pm 0.7$ & 0.86 \\
\hline Isolated medial meniscal allografts & $4.4 \pm 2.6$ & $4.0 \pm 1.7$ & 0.64 & $2.3 \pm 0.8$ & $2.4 \pm 0.8$ & 0.76 \\
\hline
\end{tabular}

techniques, types of surgical fixation, concomitant procedures, clinical scoring systems, and, very importantly, follow-up times ${ }^{24,25}$.

Our study showed that transplantation of medial and lateral meniscal allografts significantly reduces pain and improves function of the involved knee joint as measured with the modified HSS score. Our findings substantiate previously published reports on the clinical success of this procedure $e^{4,724-26}$.

Since the rate of clinical success of any surgical procedure is strongly dependent on the duration of follow-up, we performed a Kaplan-Meier survival analysis. In this analysis, it is assumed that all patients had the operation simultaneously. We compared survival times and rates among different groups of patients treated with transplantation of a viable meniscal allograft. The mean survival times and cumulative survival rates were comparable between the lateral and medial allografts. In contrast, van Arkel and de Boer noted a considerable difference between these two types of grafts in their series, in which the mean survival times were 9.25 and 5.75 years for the lateral and medial allografts, respectively, and the survival rates were $76.54 \%$ at ten years for the lateral allografts and $50.6 \%$ at nine years for the medial allografts ${ }^{27}$. In their study, the Lysholm score and arthroscopic findings were used to define clinical failures of cryopreserved allografts fixed with a comparable soft-tissue technique. The greater survival time and rate for the medial allografts in our series compared with those in other reports ${ }^{27}$ can be attributed to the lower number of anterior cruciate-deficient knees in our series. Increased anterior tibial translation due to deficiency of the anterior cruciate ligament is known to induce higher stress on the medial meniscus and therefore can induce secondary graft detachment and failure ${ }^{27}$.

We performed a survival analysis on twenty cases of isolated medial allograft transplantation and forty-nine cases of isolated lateral allograft transplantation. Again, survival times and rates were observed to be comparable between the two groups.

The failure rates and survival times differed between the isolated medial meniscal allografts transplanted into a wellaligned lower limb and the medial meniscal allografts combined with a high tibial osteotomy to correct varus malalignment. Combining the medial allograft procedure with a high tibial osteotomy appears to result in longer allograft survival and fewer failures. We hypothesized that the shift of the mechani- cal axis toward the lateral compartment unloads the medial meniscal allograft and thus makes it less prone to failure, even though the initial cartilage degeneration at the time of transplantation was more severe in the group treated with the osteotomy. However, it cannot be concluded that a high tibial osteotomy should be performed in association with medial meniscal transplantation in a limb with normal axial alignment. Rather, it can be concluded that transplantation of a medial meniscal allograft in a varus-aligned knee should be combined with a high tibial osteotomy since varus malalignment is an absolute contraindication to transplantation of a medial meniscal allograft ${ }^{5,18,25-28}$.

Overall, twenty-one of the 100 viable allografts in our study failed at a mean of $5.4 \pm 3.3$ years. The failure rate was $28 \%$ for the medial allografts, at a mean of $6.0 \pm 8.8$ years, compared with $16 \%$ for the lateral allografts, at a mean of 4.8 \pm 2.8 years. The fact that the failure rate for the medial allografts was higher than that for the lateral allografts can be explained by the longer mean duration of follow-up for the former group. The follow-up was longer because the number of indications for medial allograft transplantation at our institution was higher in the early years of this study. The number of patients with a total meniscectomy in the medial compartment and associated pain has decreased since then. However, because the lateral meniscus plays a greater role in stress protection, a lateral meniscectomy can result in a painful knee more rapidly, leading to the higher number of knees treated with transplantation of a lateral meniscal allograft with a shorter mean follow-up time ${ }^{2}$.

The overall rate of failure of the viable meniscal allografts in our study is consistent with previously published mediumterm and long-term data on deep-frozen and cryopreserved allografts fixed with a bone-plug or soft-tissue technique ${ }^{4,5,7}$. Our overall failure rate of $21 \%$ is, however, clearly lower than the failure rates of deep-frozen, irradiated allografts (failure rate, $44 \%$ ) or lyophilized allografts $s^{4,28}$. Both preservation techniques are known to render the graft acellular and may adversely affect the material properties of the graft ${ }^{29-32}$. Cultured menisci have been shown to remain viable and to continue to produce extracellular matrix compounds-hence, the term "viable meniscal allograft." ${ }^{14}$ After a two-week culture period, the meniscus is transplanted into the recipient knee. The proportion of cells 
The Journal of BOnE \& JOINT SuRgery - JBJS.ORG

TABLE VI (continued)

\begin{tabular}{|c|c|c|c|c|c|}
\hline \multicolumn{3}{|c|}{ Preop. Pain Score (points) } & \multicolumn{3}{|c|}{ Preop. Function Score (points) } \\
\hline Non-Failures* & Failures* & $P$ Value & Non-Failures* & Failures* & P Value \\
\hline $14.4 \pm 8.2$ & $6.4 \pm 5.0$ & 0.008 & $62.4 \pm 20.9$ & $50.0 \pm 27.9$ & 0.34 \\
\hline $16.0 \pm 9.7$ & $5.0 \pm 7.1$ & 0.18 & $61.0 \pm 12.0$ & $70.0 \pm 14.2$ & 0.36 \\
\hline $15.0 \pm 6.7$ & $5.7 \pm 5.3$ & 0.013 & $66.7 \pm 20.7$ & $45.0 \pm 32.4$ & 0.23 \\
\hline $14.9 \pm 9.3$ & $14.4 \pm 10.1$ & 0.99 & $61.1 \pm 17.2$ & $61.1 \pm 25.3$ & 0.96 \\
\hline $15.4 \pm 9.3$ & $15.0 \pm 10.7$ & 0.96 & $60.9 \pm 18.4$ & $64.4 \pm 25.0$ & 0.67 \\
\hline
\end{tabular}

that survive and how long they survive in vivo are unknown. Jackson et al. used DNA probe analysis in a goat model and found that all donor cells were rapidly replaced by host cells over a period of four weeks ${ }^{33}$. However, a previous study performed in our department demonstrated the presence of donor DNA in the viable human meniscal allograft for as long as sixty-four months after transplantation, indicating that donor cells remain viable for a longer period and the replacement process by host cells is probably slower in the human model ${ }^{20}$. The biomechanical function of the meniscal allograft depends not only on the quality of the surgical fixation technique, but also on the phenotype of the cell population of the allograft. It is not known if recipient meniscus-invading cells, probably derived from the synovial lining, have the same capacity to produce extracellular matrix as have native meniscus cells ${ }^{8,34}$. It was hypothesized at the start of this study that the use of viable meniscal allografts would be more beneficial than the use of acellular grafts (deep-frozen, lyophilized, or cryopreserved grafts). The failure rates and survival times in this study were comparable with previously published data, but a clear benefit could not be demonstrated for viable meniscal allografts.

Previous studies have shown that meniscal allografts are more prone to failure when they are implanted into severely degenerated or malaligned knee joints ${ }^{28,35,36}$. Nonetheless, with the numbers available, our results did not indicate any significant difference between failures and successful allografts with regard to these parameters at the time of transplantation. The preoperative pain score, however, was found to be a negative predictor of clinical failure in the overall medial allograft group as well as in the isolated medial allograft subgroup.

A majority of the failures was characterized by progressive degeneration of the articular cartilage, and all but one was associated with degeneration of the meniscal allograft. As we did not evaluate the status of the articular cartilage and the meniscal allograft at the time of the latest follow-up of the successful cases, we can conclude only that degeneration of the articular cartilage correlates moderately with degeneration of the meniscal allograft at the time of failure. This indicates an intricate relationship between these two articular components.

There is still uncertainty about the best surgical fixation technique $^{37}$. Several in vitro biomechanical studies on human cadaveric knees have shown that, for both the medial and the lateral meniscus, bone-plug fixation provides better strength than does soft-tissue fixation ${ }^{8-11}$. However, the authors of these studies did not take into account the biomechanical behavior after the allograft had healed to the meniscal rim. It had not been documented that bone-plug fixation or soft-tissue fixation leads to longer survival or better clinical results $s^{24,25}$.

This study also had limitations. First, the criteria for failure were based on clinical and arthroscopic findings. There may have been meniscal implants that were substantially degenerated, torn, or unstable but were asymptomatic and thus not considered a failure. These cases could have been identified by magnetic resonance imaging, which has an established role in the diagnosis of meniscal lesions. However, the correlation between the findings of magnetic resonance imaging and the clinical outcome is still at issue $e^{22,23,38}$.

A second limitation of our study was that the involved knee joints were evaluated clinically with the modified HSS scoring system ${ }^{17}$, which was originally designed for the evaluation of patients undergoing knee joint arthroplasty. When we started our study in 1989, no other clinical scoring system was available for evaluating the clinical outcome of meniscal allograft transplantation. Even today, meniscal allograft procedures are being evaluated with a variety of scoring systems, indicating the lack of a "gold-standard" evaluation system. This hampers comparison with results published elsewhere.

Third, as a result of the wide variability in surgical techniques, concomitant procedures, and clinical scoring systems described in the literature, it is impossible to ascertain whether viable meniscal allografts have more clinical benefit than do cryopreserved or deep-frozen allografts. A controlled study should be able to shed more light on this interesting topic.

In conclusion, this study showed that transplantation of a viable meniscal allograft significantly reduces pain and improves function of the knee joint after meniscectomy. This beneficial effect remained in approximately $70 \%$ of the patients at ten years after the surgery. Ultimately, this study identified the need for a prospective study comparing patients with similar symptoms and clinical findings treated with and without a meniscal allograft and followed for a longer period with use of clinical evaluation as well as more objective documentation tools to measure the actual fate of the allograft itself and the articular cartilage. 
The Journal of Bone \& JoINT SURGERY · JBJS.ORG VOlume 87-A · Number 4 · April 2005
TRANSPLANTATION OF

Viable Meniscal Allograft

\section{Appendix}

Tables presenting individual patient data, the modified HSS eA scoring system, and scatter plots of the failures are available with the electronic versions of this article, on our web site at jbjs.org (go to the article citation and click on "Supplementary Material") and on our quarterly CD-ROM (call our subscription department, at 781-449-9780, to order the CD-ROM).

Peter C.M. Verdonk, MD

Alex Demurie, MD

Karl Fredrik Almqvist, MD, PhD

Eric M. Veys, MD, PhD

Gust Verbruggen, MD, PhD

René Verdonk, MD, PhD
Departments of Physical Medicine and Orthopaedic Surgery (P.C.M.V., A.D., K.F.A., and R.V.) and Rheumatology (E.M.V. and G.V.), Ghent University Hospital, De Pintelaan 185, B-9000 Ghent, Belgium. E-mail address for P.C.M. Verdonk: pverdonk@yahoo.com

In support of their research or preparation of this manuscript, one or more of the authors received grants or outside funding from the Fund for Scientific Research (F.W.O.-Vlaanderen), Flanders, Belgium. None of the authors received payments or other benefits or a commitment or agreement to provide such benefits from a commercial entity. No commercial entity paid or directed, or agreed to pay or direct, any benefits to any research fund, foundation, educational institution, or other charitable or nonprofit organization with which the authors are affiliated or associated.

doi:10.2106/JBJS.C.01344

\section{References}

1. Fairbank TJ. Knee joint changes after meniscectomy. J Bone Joint Surg Br. 1948;30:664-70.

2. Chatain F, Adeleine P, Chambat P, Neyret P; Societe Francaise d'Arthroscopie. A comparative study of medial versus lateral arthroscopic partial meniscectomy on stable knees: 10-year minimum follow-up. Arthroscopy. 2003;19:842-9.

3. Englund M, Roos EM, Lohmander LS. Impact of type of meniscal tear on radiographic and symptomatic knee osteoarthritis: a sixteen-year followup of meniscectomy with matched controls. Arthritis Rheum. 2003;48:2178-87.

4. Wirth CJ, Peters G, Milachowski KA, Weismeier KG, Kohn D. Long-term results of meniscal allograft transplantation. Am J Sports Med. 2002;30:174-81.

5. van Arkel ER, de Boer HH. Human meniscal transplantation. Preliminary results at 2 to 5-year follow-up. J Bone Joint Surg Br. 1995;77:589-95.

6. DeHaven KE. Meniscus repair. Am J Sports Med. 1999;27:242-50.

7. Rath E, Richmond JC, Yassir W, Albright JD, Gundogan F. Meniscal allograft transplantation. Two- to eight-year results. Am J Sports Med. 2001;29:410-4.

8. Paletta GA Jr, Manning T, Snell E, Parker R, Bergfeld J. The effect of allograft meniscal replacement on intraarticular contact area and pressures in the human knee. A biomechanical study. Am J Sports Med. 1997;25:692-8.

9. Huang A, Hull ML, Howell SM. The level of compressive load affects conclusions from statistical analyses to determine whether a lateral meniscal autograft restores tibial contact pressure to normal: a study in human cadaveric knees. J Orthop Res. 2003;21:459-64.

10. Chen MI, Branch TP, Hutton WC. Is it important to secure the horns during lateral meniscal transplantation? A cadaveric study. Arthroscopy. 1996;12: 174-81.

11. Alhalki MM, Howell SM, Hull ML. How three methods for fixing a medial meniscal autograft affect tibial contact mechanics. Am J Sports Med. 1999;27:320-8.

12. Aagaard $\mathrm{H}$, Jorgensen $U$, Bojsen-Moller F. Immediate versus delayed meniscal allograft transplantation in sheep. Clin Orthop. 2003;406:218-27.

13. Outerbridge RE. The etiology of chondromalacia patellae. J Bone Joint Surg Br. 1961;43:752-7.

14. Verbruggen $G$, Verdonk $R$, Veys EM, Van Daele P, De Smet P, Van den Abbeele $\mathrm{K}$, Claus B, Baeten D. Human meniscal proteoglycan metabolism in long-term tissue culture. Knee Surg Sports Traumatol Arthrosc. 1996;4:57-63.

15. Verdonk R, Van Daele P, Claus B, Vandenabeele K, Desmet P, Verbruggen G, Veys EM, Claessens H. [Viable meniscus transplantation]. Orthopäde. 1994;23:153-9. German.

16. Vorlat P, Verdonk R, Arnauw G. Long-term results of tendon allografts for anterior cruciate ligament replacement in revision surgery and in cases of combined complex injuries. Knee Surg Sports Traumatol Arthrosc. 1999;7:318-22.

17. Insall JN, Dorr LD, Scott RD, Scott WN. Rationale of the Knee Society clinica rating system. Clin Orthop. 1989;248:13-4.

18. Verdonk R. Alternative treatments for meniscal injuries. J Bone Joint Surg Br. 1997;79:866-73.

19. Shasha N, Krywulak S, Backstein D, Pressman A, Gross AE. Long-term followup of fresh tibial osteochondral allografts for failed tibial plateau fractures. J Bone Joint Surg Am. 2003;85(Suppl 2):33-9.
20. Verdonk P, Almqvist KF, Lootens T, Van Hoofstat D, Van Den Eeckhout $E$, Verbruggen $G$, Verdonk R. DNA fingerprinting of fresh viable meniscal allografts transplantated in the human knee [abstract]. Osteoarthritis Cartilage. 2002;10(Suppl A):S43:S44.

21. Steenbrugge $F$, Verdonk $R$, Verstraete $K$. Long-term assessment of arthro scopic meniscus repair: a 13-year follow-up study. Knee. 2002;9:181-7.

22. Verstraete KL, Verdonk R, Lootens T, Verstraete P, De Rooy J, Kunnen M. Current status and imaging of allograft meniscal transplantation. Eur J Radiol. 1997;26:16-22.

23. van Arkel ER, Goei R, de Ploeg I, de Boer HH. Meniscal allografts: evaluation with magnetic resonance imaging and correlation with arthroscopy. Arthroscopy. 2000;16:517-21.

24. Peters G, Wirth CJ. The current status of meniscal allograft transplantation and replacement. Knee. 2003;10:19-31.

25. Cole BJ, Carter TR, Rodeo SA. Allograft meniscal transplantation: background, techniques, and results. Instr Course Lect. 2003;52:383-96.

26. Milachowski KA, Weismeier K, Wirth $\mathrm{CJ}$. Homologous meniscus transplantation. Experimental and clinical results. Int Orthop. 1989;13:1-11.

27. van Arkel ER, de Boer HH. Survival analysis of human meniscal transplantations. J Bone Joint Surg Br. 2002;84:227-31.

28. Noyes FR, Barber-Westin SD. Irradiated meniscus allografts in the human knee. Orthop Trans. 1989;19:417.

29. Fabbriciani C, Lucania L, Milano G, Schiavone Panni A, Evangelisti M. Meniscal allografts: cryopreservation vs deep-frozen technique. An experimental study in goats. Knee Surg Sports Traumatol Arthrosc. 1997;5:124-34.

30. Belkoff SM, Haut RC. Microstructurally based model analysis of gammairradiated tendon allografts. J Orthop Res. 1992;10:461-4.

31. Cheung DT, Perelman N, Tong D, Nimni ME. The effect of gamma-irradiation on collagen molecules, isolated alpha-chains, and crosslinked native fibers. J Biomed Mater Res. 1990;24:581-9.

32. De Deyne P, Haut RC. Some effects of gamma irradiation on patellar tendon allografts. Connect Tissue Res. 1991;27:51-62.

33. Jackson DW, Whelan J, Simon TM. Cell survival after transplantation of fresh meniscal allografts. DNA probe analysis in a goat model. Am J Sports Med. 1993;21:540-50.

34. Rodeo SA, Seneviratne A, Suzuki K, Felker K, Wickiewicz TL, Warren RF. Histological analysis of human meniscal allografts. A preliminary report. J Bone Joint Surg Am. 2000;82:1071-82.

35. Cameron JC, Saha S. Meniscal allograft transplantation for unicompartmental arthritis of the knee. Clin Orthop. 1997;337:164-71.

36. de Boer $\mathrm{HH}$, Koudstaal J. Failed meniscus transplantation. A report of three cases. Clin Orthop. 1994;306:155-62.

37. Messner K, Verdonk R. It is necessary to anchor the meniscal transplants with bone plugs? A mini-battle. Scand J Med Sci Sports. 1999;9:186-7.

38. Potter HG, Rodeo SA, Wickiewicz TL, Warren RF. MR imaging of meniscal allografts: correlation with clinical and arthroscopic outcomes. Radiology. 1996; 198:509-14. 